\section{P3.392 INCREASING YOUTH AND ADOLESCENT ACCESS TO SEXUAL AND REPRODUCTIVE HEALTH SERVICES PREVENTS STIS}

doi:10.1136/sextrans-2013-051184.0845

B Kayongo. Adolescent Reproductive Health Advocates, Mongu, Zambia

Background Following the ministry of health reports that indicated high incidences of late reporting of STIs by youths in 2009, ARHA conducted a baseline survey to ascertain the cause of the problem. The findings reviewed that most of the youths who reported STIs to clinics in the affected areas received stigma from the health staff, others feared to disclose their conditions to their parents due to traditional factors. Youths who fall prey to STIs preferred traditional medicines for cure while. In 2011, a youth access project was launched in three affected districts of Western Province in Zambia. It aimed at reducing STIs transmission by increasing youth access to sexual and reproductive health services.

Methods Three key methods were used;

1. Household Approach: - The household approach was initiated to win support of parents. Peer educators adopted households with permission from parents and conducted peer education sessions with youths on STIs prevention during their spare time. Adult mentors were also trained to promote parent to child dialogue on sexuality issues in all the adopted households

2. Information and condom distribution booth: - booths were placed in strategic places within the project areas to offer IEC, referrals and condoms. Booths were managed by peer educators.

3. Youth Friendly Corners: - youths were trained as lay counsellors and youth friendly corners were established in health facilities. The ministry of health attached trained health personnel to offer clinical services. The youth friendly corners received referrals from households, booths and STIs cases from the Out patient department.

Results By the end of 2011, youths accessed information on how they can prevent STIs screened and treated for STIs. Cases of STIs among the youths in the project sites have reduced. The demand for condoms has also increased in the project sites.

Conclusion Increasing access to SRHS among youth prevents STIs.

\section{P3.393 IKNOWMINE.ORG - A COMPREHENSIVE WELLNESS WEBSITE FOR ALASKA NATIVE YOUTH}

doi:10.1136/sextrans-2013-051184.0846

C Jessen, T Revels, J Ferguson. Alaska Native Tribal Health Consortium, Anchorage, AK, United States

Background Alaska has some of the highest rates of Chlamydia and gonorrhoea in the United States. The Centers for Disease Control and Prevention (CDC) ranked Alaska \#1 for Chlamydia and \#3 for gonorrhoea in 2010. When iknowmine.org first launched in December 2009, Alaska was experiencing a gonorrhoea outbreak and endemic rates of Chlamydia. Alaska Native people, especially youth and women, shouldered the largest burden. Evidence from a focus group project with Alaska Native youth suggested that sexual health initiatives need to use the internet to reach adolescents with STD/HIV education and testing messages.

Methods To help Alaska Native youth on their wellness journey, iknowmine was recreated as a culturally appropriate, readily accessible and comprehensive youth health resource addressing many issues that matter to youth - relationships, emotional health, nutrition, safety, drug and alcohol use and sexual health. On iknowmine. org youth can find accurate health information on a variety of topics, text to ask health questions and order free condoms and at-home STD testing kits, download educational materials, watch digital storeys and more. The website also incorporates social media like Facebook and Twitter to reach a larger audience.
Results Between January 2010 and January 2013, 23,887 new visitors frequented iknowmine.org. Since its inception, 514 visitors have registered as iknowmine users. Iknowmine.org has received 226 condom orders, which equals about 4,520 condoms that were mailed to rural and urban Alaska residents. Free at-home STD testing is offered through a partnership with the Johns Hopkins University's I Want the Kit (IWTK) programme. In 2012, 342 testing kits were ordered and 132 returned with an overall return rate of $39 \%$. Among returned kits, 14 participants tested positive for Chlamydia, two for gonorrhoea and Chlamydia and four for trichomonas.

Conclusion Iknowmine.org has been successful in reaching a large audience with HIV/STD education and resources.

\section{P3.394 STREET HIV TESTING OF YOUTH IS PERSUASIVE PREVENTION TECHNIQUE FOR HARD-TO-REACH ADOLESCENTS}

doi:10.1136/sextrans-2013-051184.0847

\section{J B Chittick. TeenAIDS-PeerCorps, Norfolk, VA, United States}

Background With adolescent STI rates climbing, novel techniques for prevention must be used to stem new cases. The advent of home HIV test kits for over the counter sales in the U.S. is an efficacious way to also test youth in public venues in a quick and easy manner. The result is an underutilised tool that works as a deterrent to unprotected sex.

Methods Beginning in November 2012 after the introduction of home HIV test kits, a Harvard-trained youth AIDS expert began testing teens on the streets and at their favourite public gathering spots in Norfolk, Virginia, the city with the highest HIV/STI rates in the state. Because the oral swab technology is easy to administer with results in 20 minutes (no CLIA or lab work is necessary), the testing is popular among curious youth. No AIDS stigma exists when testing is done among peers outside hospital/clinics.

Results Over 45 public tests were administered to at least one person among groups of teens at parks, malls, at beaches and on the streets. During the 20 minutes waiting for results, the experienced tester provided medically accurate information and counselling to the teens that asked probing questions of peer concern. Youth were surprised how easy the process was and that it could be done in private with a sexual partner. In the case of two HIV-positive tests (a 16- and a 17-year old), they were immediately taken for a confirmatory blood test.

Conclusion Youth were impressed that tests were available without a doctor's visit, a prescription, the need to be tested in a hospital or importantly, without parents' knowledge. In every group of three or more, one adolescent was publicly tested. Immediately they used cell phones to send texts and pictures to a wider audience using favourable descriptions.

\section{P3.395 GENDER-BASED SERVICES IN A COMMUNITY CENTRE "WOMEN TO WOMEN"}

doi:10.1136/sextrans-2013-051184.0848

O Vasylieva, I Potapova. Youth non-government organization "Youth centre for women's initiatives", Sevastopol, Ukraine

The women are the most vulnerable to HIV group, as a consequence of their biological particularities and stereotypes existing in society, being the most stigmatised, closed, dependent on their male partner. Their part in the prophylactic programmes of Sevastopol is only $13 \%$ (according to the Syrex project data). Thanks to the UNODC financial support and with the social centre for drug consumers of "Youth centre for women's initiatives" as the base, a centre named "Woman to Woman" was opened. The centre worked one day a week as a "social supermarket". A comfortable and attractive meeting place for female clients was the project's key element. On that day, the services 
could be used only by women, and the services list was extended with special services for the women that were selected according to the results of a focus group. The additional services were informational classes with a psychologist, lawyer, social worker, individual consultations with a therapist, infectious disease specialist, gynaecologist, etc., an opportunity to participate in the Creative studio, manicure and haircut, a self-aid group, food and hygienic kits for women and children. The services were provided by female specialists only, including the use of the "Equal to Equal" method. At the meetings, information regarding to the women's health and rights was brought to the clients so that they were able to feel more confident and based their choices on better informed decisions.

From May to October of 2012, more than 300 female drug consumers were involved in the project's services. Among them, a volunteer group ( 9 women) was prepared for the future prophylactic work with women. The project's activity demonstrated its actuality and the need for it to be continued. During the project implementation the participation of female drug consumers reached $32 \%$.

\section{P3.396 ARE THE WORLD AIDS CONFERENCES GUILTY OF GENDER BIAS? EVIDENCE FROM TRENDS IN THE MONITORING OF WAC SCIENTIFIC DISCOURSE FROM 1989 TO 2012}

doi:10.1136/sextrans-2013-051184.0849

'B E Spencer, ${ }^{2} \mathrm{~A}$ Jeannin, ${ }^{2} \mathrm{~F}$ Dubois-Arber, ${ }^{3 \mathrm{P}}$ Iriarte. ${ }^{1}$ Institute of Social and Preventive Medicine (IUMSP), Lausanne University Hospital, Lausanne, Switzerland; 'Institute of Social and Preventive Medicine (IUMSP), Lausanne University Hospital, Lausanne, Switzerland; 'Public Health Documentation Centre (CDSP), Lausanne University Hospital, Lausanne, Switzerland

Background The issue of gender is acknowledged as a key issue for the AIDS epidemic. World AIDS Conferences (WAC) have constituted a major discursive space for the epidemic. We sought to establish the balance regarding gender in the AIDS scientific discourse by following its development in the published proceedings of WAC. Fifteen successive WAC 1989-2012 served to establish a "barometer" of scientific interest in heterosexual and homo/bisexual men and women throughout the epidemic. It was hypothesised that, as in other domains of Sexual and Reproductive Health, heterosexual men would be "forgotten" partners.

Method Abstracts from each conference were entered in electronic form into an Access database. Queries were created to generate five categories of interest and to monitor their annual frequency. All abstract titles including the term "men" or "women" were identified. Collections of synonyms were systematically and iteratively developed in order to classify further abstracts according to whether they included terms referring to "homo/bisexual" or "heterosexual". Reference to "Mother to Child Transmission" (MTCT) was also flagged. Results The category including "men", but without additional reference to "homo-bisexuel" (i.e. referring to men in general and/or to heterosexual men) consistently appears four times less often than the equivalent category for women. Excluding abstracts on women and MTCT has little impact on this difference. Abstracts including reference to both "men" and "homo-bisexual" emerge as the secondmost frequent category; presence of the equivalent category for women is minimal.

Conclusion The hypothesised absence of heterosexual men in the AIDS discourse was confirmed. Although the relative presence of homo-bisexual men and women as a focal subject may be explained by epidemiological data, this is not so in the case of heterosexual men and women. This imbalance has consequences for HIV prevention.

\section{P3.397 PREVENTION SERVICES, HEALTH-SEEKING BEHAVIOURS, AND STI PREVALENCE AMONG FEMALE ENTERTAINMENT WORKERS IN CAMBODIA}

doi:10.1136/sextrans-2013-051184.0850
'W P Killam, ${ }^{2} \mathrm{P}$ Mun, ${ }^{3} \mathbf{J}$ D Mutuc, ${ }^{2} \mathrm{~N}$ Chann, ${ }^{4} \mathrm{~S}$ Chan, ${ }^{1} \mathrm{R}$ W Shiraishi, ${ }^{1} \mathrm{D}$ Warren, ${ }^{2} \mathrm{M}$ C Vun. 'Centers for Disease Control and Prevention, Center for Global Health, Atlanta, GA, United States, ${ }^{2}$ National Center for HIVIAIDS, Dermatology and STDs, Ministry of Health, Phnom Penh, Cambodia, ${ }^{3}$ Association of Schools of Public Health/Centers for Disease Control and Prevention Allan Rosenfield Global Health Fellow, Phnom Penh, Cambodia, ${ }^{4}$ US Centers for Disease Control and Prevention, Cambodia Country Office, Phnom Penh, Cambodia

Background Cambodia's brothel-based prevention programmes successfully promoted condom use among female sex workers since 1994. HIV and sexually transmitted infection (STI) prevalence decreased precipitously from 1998 to 2006. In 2008 brothels became illegal, and entertainment venues (karaoke bars, beer gardens and massage parlours) increased rapidly. Many female entertainment workers (FEWs) at these venues provide transactional sex. We explored receipt of prevention services and associated knowledge, health-seeking behaviour, and prevalence of STIs and HIV among Cambodian FEWs.

Methods In 2011, a stratified multi-stage cluster survey was conducted among 2,564 FEWs in selected provinces of Cambodia. Voluntary, anonymous interviews collected information on receipt of prevention services and sexual behaviours. Biological testing was conducted for HIV, syphilis, gonorrhoea, and chlamydia. Analyses were weighted and controlled for the design of the survey. Logistic regression models were used to examine associations between interventions, health-seeking behaviours, and STIs.

Results Prevalence of any STI and HIV was $20.8 \%$ and $2.6 \%$, respectively. Among FEWs, 86.9\% reported receiving HIV/STI education, most commonly from an outreach worker $(47.7 \%)$ or television (46.1\%). Receipt of a prevention message was associated with getting an HIV test (odds ratio [OR] $=2.6,95 \%$ confidence interval [CI]: 1.8-3.6) and sexual health check-up (OR $=2.6,95 \%$ CI: $1.7-$ 3.9 ) in the last 12 months, and higher HIV knowledge ( $O R=1.7$, 95\% CI: 1.1-2.8). Condom provision was also associated with health-seeking behaviours. Receipt of prevention interventions was not associated with reported recent condom usage or STIs, although further analyses are ongoing in order to adjust for potential confounders.

Conclusion The rapid expansion of non-brothel-based entertainment work challenges prevention efforts among Cambodian FEW, who have high STI prevalence and risk behaviours. Prevention education and condom provision are associated with increased knowledge and health seeking behaviours, but not self-reported condom use or reduced STI prevalence in this cross-sectional snapshot.

\section{P3.398 SENTINEL SURVEILLANCE AND PREVENTION OF SEXUALLY TRANSMITTED INFECTIONS AMONG FEMALE SEX WORKERS IN GUATEMALA: FIRST FINDINGS FROM VICITS}

doi:10.1136/sextrans-2013-051184.0851

C A Galindo Arandi, I Loya, J Jacobson, F Arana, S Morales Miranda. Universidad de/ Valle de Guatemala, Guatemala, Guatemala

Background In Guatemala, female sex workers (FSWs) have historically demonstrated a high HIV prevalence and are considered a key group in heterosexual HIV transmission. A system for sentinel surveillance of HIV-STI infection, risk behaviours and STI control targeting FSW, incorporating prevention components (VICITS) was rolled at public health centres in four Guatemalan cities, beginning in 2007, 2008, 2010 and 2011, respectively. We present the first assessment of scale-up, retention and HIV-STI infection trends among VICITS users.

Methods The number of FSW accessing VICITS each year in 2007-2011 was estimated by health centre based on a unique, person-level identifier. Retention was estimated as the percent of new users accessing VICITS in a given year who returned for at least one control visit. Percent of users infected was estimated from regular, 